\title{
Stand-alone tsunami alarm equipment
}

\author{
Akio Katsumata ${ }^{1}$, Yutaka Hayashi $^{1}$, Kazuki Miyaoka ${ }^{1}$, Hiroaki Tsushima ${ }^{1}$, Toshitaka Baba ${ }^{2}$, Patricio A. Catalán ${ }^{3,4,5}$, \\ Cecilia Zelaya $^{6}$, Felipe Riquelme Vasquez ${ }^{7}$, Rodrigo Sanchez-Olavarria ${ }^{8}$, and Sergio Barrientos ${ }^{8}$ \\ ${ }^{1}$ Meteorological Research Institute, Japan Meteorological Agency, Nagamine 1-1, Tsukuba, Ibaraki Prefecture, Japan \\ ${ }^{2}$ Tokushima University, Shinkura-cho 2-24, Tokushima, Tokushima Prefecture, Japan \\ ${ }^{3}$ Departamento de Obras Civiles, Universidad Técnica Federico Santa María, Avenida España 1680, Valparaíso, \\ Región de Valparaíso, Chile \\ ${ }^{4}$ Centro Nacional de Investigación para la Gestión Integrada de Desastres Naturales, CONICYT/FONDAP/1511007, \\ Avenida Vicuña Mackenna 4860, Santiago, Región Metropolitana, Chile \\ ${ }^{5}$ Centro Científico Tecnológico de Valparaíso-CCTVal, Universidad Técnica Federico Santa María, Avenida España 1680, \\ Valparaíso, Región de Valparaíso, Chile \\ ${ }^{6}$ Hydrographic and Oceanographic Service, Chilean Navy, Errázuriz Echaurren 254, Playa Ancha, Región Valparaíso, Chile \\ ${ }^{7}$ National Office of Emergency of the Interior Ministry, Calle Beaucheff 1671, Santiago, Región Metropolitana, Chile \\ ${ }^{8}$ University of Chile, Av Libertador Bernardo O’Higgins 1058, Santiago, Región Metropolitana, Chile \\ Correspondence to: Akio Katsumata (akatsuma@mri-jma.go.jp)
}

Received: 12 May 2016 - Discussion started: 21 June 2016

Revised: 7 April 2017 - Accepted: 11 April 2017 - Published: 15 May 2017

\begin{abstract}
One of the quickest means of tsunami evacuation is transfer to higher ground soon after strong and long ground shaking. Ground shaking itself is a good initiator of the evacuation from disastrous tsunami. Longer period seismic waves are considered to be more correlated with the earthquake magnitude. We investigated the possible application of this to tsunami hazard alarm using single-site ground motion observation. Information from the mass media is sometimes unavailable due to power failure soon after a large earthquake. Even when an official alarm is available, multiple information sources of tsunami alert would help people become aware of the coming risk of a tsunami. Thus, a device that indicates risk of a tsunami without requiring other data would be helpful to those who should evacuate. Since the sensitivity of a low-cost MEMS (microelectromechanical systems) accelerometer is sufficient for this purpose, tsunami alarm equipment for home use may be easily realized. Amplitude of long-period (20 s cutoff) displacement was proposed as the threshold for the alarm based on empirical relationships among magnitude, tsunami height, hypocentral distance, and peak ground displacement of seismic waves. Application of this method to recent major earthquakes indicated that such
\end{abstract}

equipment could effectively alert people to the possibility of tsunami.

\section{Introduction}

Early-stage tsunami warnings are usually issued by governmental organizations, based on the estimated hypocenter and magnitude. Magnitude, a crucial factor for tsunami forecasting, is estimated based on amplitude of the seismic wave (Katsumata et al., 2013), rapid estimation of seismic moment (Tsuboi et al., 1995), or high-frequency energy radiation (Hara, 2007).

If earthquake magnitude can be estimated using ground motion at a single site, residents can be alerted to evacuate before a potential tsunami. While strong ground motion indicates relatively large magnitude, it does not always mean tsunami hazard. Small, nearby earthquakes may have ground motion as strong as larger, more distant ones. Strong ground motion alone is therefore not a reliable indicator of tsunami hazard, so simply telling people to evacuate if they feel strong shaking is not enough. However, some people are reluctant to evacuate even after receiving an official tsunami 
warning. We feel that multiple independent warnings are much more compelling, provided the additional warnings are reasonably reliable. A stand-alone warning system would be valuable if the official warning were unavailable because of some mishap.

Low-cost MEMS (microelectromechanical systems) accelerometers could equip an ordinary house with such a single-station tsunami alarm. Some single-site processing methods have been proposed for earthquake early warning. Odaka et al. (2003) developed a method to estimate epicentral distance using single-site seismic data. Magnitude can be estimated based on epicentral distance and amplitude at the station. Allen and Kanamori (2003) used the $P$-wave predominant period to estimate earthquake magnitude. With tsunamis, it is not necessary to focus on the $P$-wave part of the seismic wave, because it is better to wait for completion of the fault rupture to estimate earthquake magnitude. Moreover, the high noise level of an MEMS sensor may result in considerable difference in the estimated value based on $P$-wave onset. Figure 1 presents examples of epicentral distance estimation from the onset of the $P$ wave using the method of Odaka et al. (2003), in which sharpness of the onset is used for epicentral-distance estimation. For example, with the 2003 Tokachi-oki earthquake (Fig. 1a), the difference in sharpness of onset estimated with assumption of different noise levels corresponds to 1.6 times the difference in distance. For the 2011 earthquake off the Pacific coast of Tohoku, known as the 2011 Great East Japan Earthquake (Fig. 1b), the difference in onset corresponds to 5 times the difference in distance. It is possible to use the whole seismic wave trace for tsunami evacuation purposes. Amplitude is directly related to earthquake magnitude. Strong-motion duration, which is related to earthquake magnitude (Trifunac and Brady, 1975; Dobry et al., 1978; Izutani and Hirasawa, 1987), is a candidate for single-site magnitude estimation. Although duration is a possible candidate, amplitude is used in this study. Decay of amplitude along the distance can be used to limit the area to alert.

Table 1 lists earthquakes that involved 10 or more casualties due to tsunamis around the Japanese islands in the past 100 years. This table indicates that earthquakes with a magnitude of $8(M 8)$ or greater caused serious disasters. Here we seek to differentiate earthquakes greater than $M 8$ from others. We discuss single-station seismic wave processing, focusing on possible application to stand-alone tsunami alarm equipment.

\section{Method}

We aim to distinguish events with tsunami potential from seismic data obtained at a single station. Abe (1981) presented an empirical relationship among magnitude, distance, and tsunami height as

$M_{\mathrm{t}}=\log _{10} H+a \log _{10} R+D$,
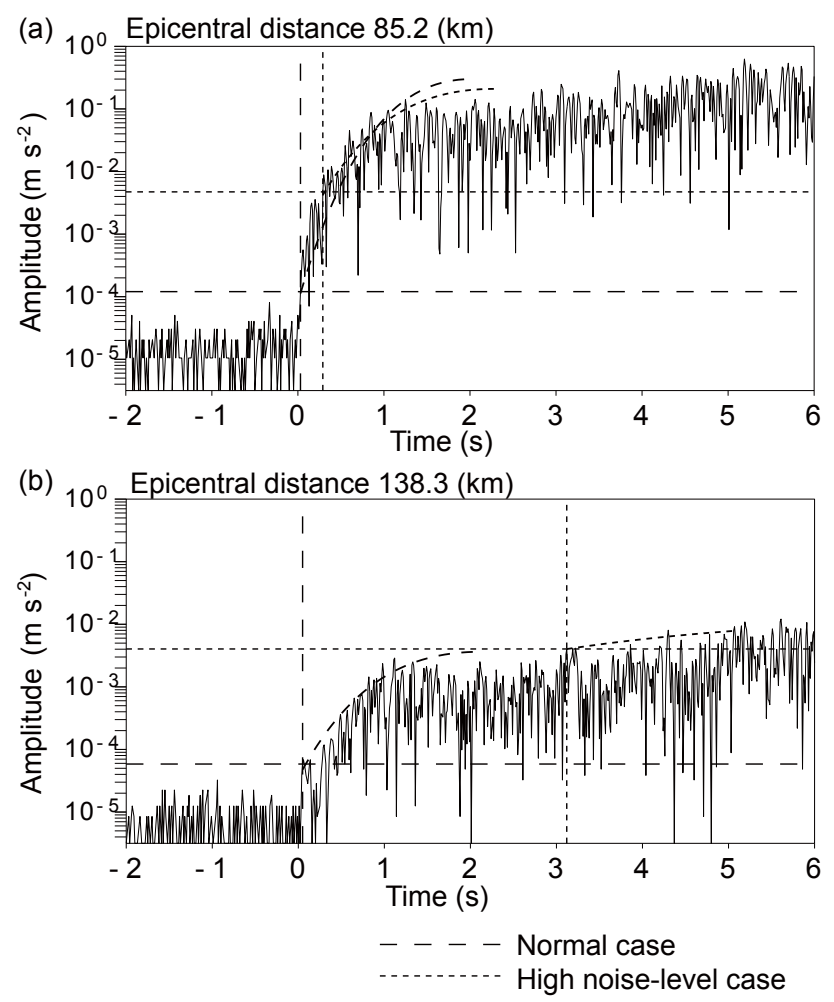

Figure 1. Examples of epicentral distance estimation using the method of Odaka et al. (2003). (a) Record of the 2003 Tokachi-oki earthquake on 26 September 2003; (b) record of the 2011 Great East Japan Earthquake on 11 March 2011. Two levels of noise were assumed. Long-dash lines: the curve of $B t \exp (-A t)$ (refer to Odaka et al., 2003) was fitted to the part where amplitude exceeded double the noise level. Short-dash lines: the curve was fitted to the part where the amplitude exceeded $0.004 \mathrm{~m} \mathrm{~s}^{-2}$, which was assumed to be twice the noise level of an MEMS sensor.

where $M_{\mathrm{t}}$ is tsunami magnitude, $H$ is the maximum amplitude of a tsunami wave in meters measured by a tide gauge, $R$ is the distance in kilometers from the epicenter to the tide station along the shortest oceanic path, and $a$ and $D$ are constants $(a=1.0, D=5.80)$. This relationship was obtained with an assumption of $M_{\mathrm{t}}=M_{\mathrm{w}} . M_{\mathrm{w}}$ denotes the moment magnitude. When $M_{\mathrm{t}}$ and $H$ are assumed, $R$ is approximately specified.

Katsumata et al. (2013) proposed a magnitude $M$ estimation method with the maximum vertical displacement amplitude $A$ of a seismic wave obtained at local distance as

$M=a_{K} \log _{10} A+b_{K} \log _{10} R_{\mathrm{h}}+c_{K}$,

where $a_{K}, b_{K}$, and $c_{K}$ are constants, and $R_{\mathrm{h}}$ is the hypocentral distance $(\mathrm{km}) . a_{K}, b_{K}$, and $c_{K}$ were adjusted with an assumption of $M=M_{\mathrm{W}}$. Katsumata et al. (2013) presented $a_{K}, b_{K}$, and $c_{K}$ in Eq. (2) for various cutoff periods. If $M_{\mathrm{t}}$ and $R$ of Eq. (1) are substituted for $M$ and $R_{\mathrm{h}}$ of Eq. (2), it is possible to convert the tsunami height $H$ to seismic wave amplitude $A$. When $M_{\mathrm{t}}$ and $H$ are assumed to be 8.0 and 
Table 1. Major disastrous earthquakes and casualties due to their tsunami around the Japanese islands in the past 100 years.

\begin{tabular}{llrc}
\hline Origin time (JST) & Epicenter & $\begin{array}{r}\text { Casualties including } \\
\text { the missing }\end{array}$ & $M$ \\
\hline 1 Sep 1923 at 11:58 & $139.14^{\circ} \mathrm{E}, 35.33^{\circ} \mathrm{N}$ & $325(105385)^{1}$ & 7.9 \\
3 Mar 1933 at 02:30 & $145.12^{\circ} \mathrm{E}, 39.13^{\circ} \mathrm{N}$ & $3064^{2}$ & 8.1 \\
2 Aug 1940 at 00:08 & $139.81^{\circ} \mathrm{E}, 42.36^{\circ} \mathrm{N}$ & $10^{2}$ & 7.5 \\
7 Dec 1944 at 13:35 & $136.18^{\circ} \mathrm{E}, 33.57^{\circ} \mathrm{N}$ & $(1251)^{2}$ & 7.9 \\
21 Dec 1946 at 04:19 & $135.85^{\circ} \mathrm{E}, 32.94^{\circ} \mathrm{N}$ & $(1443)^{2}$ & 8.0 \\
4 Mar 1952 at 10:23 & $144.15^{\circ} \mathrm{E}, 41.71^{\circ} \mathrm{N}$ & $(33)^{2}$ & 8.2 \\
26 May 1983 at $11: 59$ & $139.07^{\circ} \mathrm{E}, 40.36^{\circ} \mathrm{N}$ & $100(104)^{2}$ & 7.7 \\
12 Jul 1993 at 22:17 & $139.18^{\circ} \mathrm{E}, 42.78^{\circ} \mathrm{N}$ & $(230)^{2}$ & 7.8 \\
11 Mar 2011 at 14:46 & $142.85^{\circ} \mathrm{E}, 38.10^{\circ} \mathrm{N}$ & $18465^{3}$ & 9.0 \\
\hline
\end{tabular}

Numbers in parentheses indicate total casualties including those due to causes other than tsunami.

${ }^{1}$ Moroi and Takemura (2004). ${ }^{2}$ Usami (2003). ${ }^{3}$ National Police Agency (2015). The unified seismic catalog of Japan (Japan Meteorological Agency, 2015a) provided the epicenter and magnitude.

$2 \mathrm{~m}, R$ and $A$ become $79 \mathrm{~km}$ and $0.11 \mathrm{~m}$ for the case of a $20 \mathrm{~s}$ cutoff. The tsunami height of $2 \mathrm{~m}$ is assumed because that could cause serious damage. The magnitude of a $20 \mathrm{~s}$ cutoff, as in Katsumata et al. (2013), often agreed well with that of a $100 \mathrm{~s}$ cutoff. We can therefore choose $0.11 \mathrm{~m}$ as the threshold. If the observed amplitude is larger than this value and magnitude is 8.0, the event would be close enough to cause tsunami damage at the observation point. If the observed amplitude is larger than this value and the epicentral distance is $79 \mathrm{~km}$, the magnitude should be greater than 8.0. Equation (1) by Abe (1981) is valid in an epicentral distance range of no less than $100 \mathrm{~km}$. Since the distance of about $80 \mathrm{~km}$ is out of range, this derivation gives a very rough estimate. When $M_{\mathrm{t}}$ and $H$ are assumed at 8.5 and at $2 \mathrm{~m}, R$ and $A$ become $250 \mathrm{~km}$ and $0.07 \mathrm{~m}$ for the case of a $20 \mathrm{~s}$ cutoff. Taking into account the possibility of a larger earthquake, it is better to lower the threshold. Equation (2) has a standard deviation of $0.17\left(\sigma_{K}\right)$ as magnitude value. Therefore, we set the threshold at $0.11 / 10^{\sigma_{K}} / a_{K}=0.081 \mathrm{~m}$.

For a $50 \mathrm{~s}$ cutoff, the value of $A$ becomes $0.12 \mathrm{~m}$ for $H=$ $2 \mathrm{~m}$ from Eq. (2). A longer period is considered to be better to cope with larger events of longer source duration. However, there are instrumental limitations in any observational system. For the case of an MEMS sensor, the instrumental noise is considerably higher than that of a feedback-type accelerometer. The noise level of an MEMS accelerometer is assumed to be $0.002 \mathrm{~m} \mathrm{~s}^{-2}$ in this study, which is slightly lower than the tremor level noticeable by humans. Sensors for this level are easily available. The $0.002 \mathrm{~m} \mathrm{~s}^{-2}$ of a $20 \mathrm{~s}$ period corresponds to $0.02 \mathrm{~m}$ in displacement. For the case of a $50 \mathrm{~s}$ period, it corresponds to $0.13 \mathrm{~m}$, which is almost the same as the threshold amplitude level. Since margin is required for any kinds of observations, the case of a $50 \mathrm{~s}$ cutoff is not appropriate under this condition.

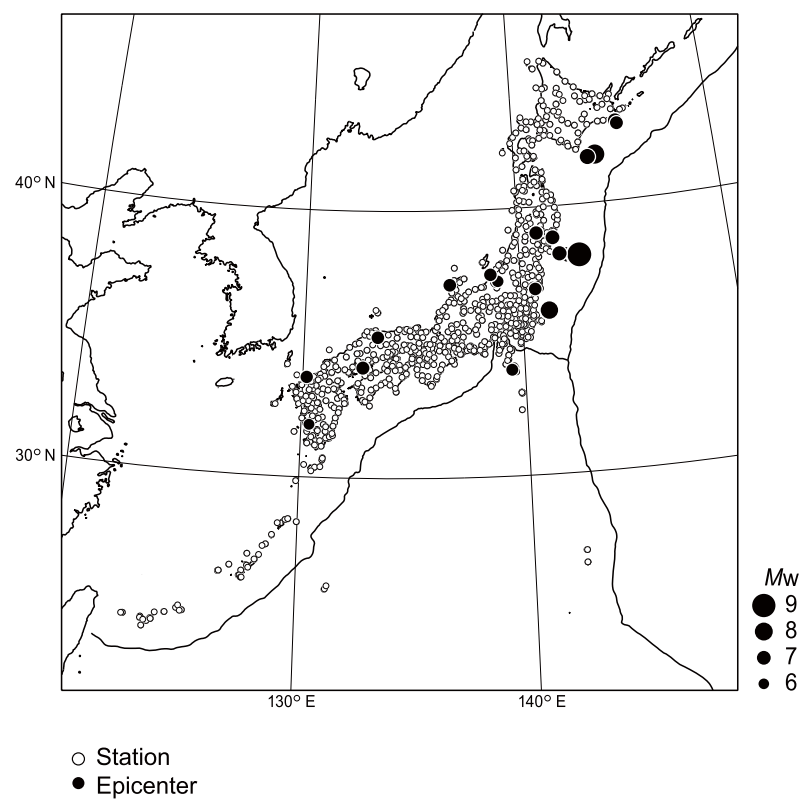

Figure 2. Station and epicenter map. Stations of seismic intensity meters (open circles) and epicenters of the events (solid circles) for which seismic records were used in this study are denoted.

\section{Results and discussion}

\subsection{Application to archived seismic records in Japan}

This method was applied to the data obtained with seismic intensity meters installed by the Japan Meteorological Agency (2015b). Station locations are indicated in Fig. 2 with the epicenters of the events for which seismic data used in this study were obtained. The result is shown in Fig. 3. The global CMT solutions (Dziewonski et al., 1981; Ekström et al., 2012) were referenced for moment magnitude $M_{\mathrm{w}}$. The red dot in Fig. 3 denotes the data exceeding the threshold $(0.081 \mathrm{~m})$, 


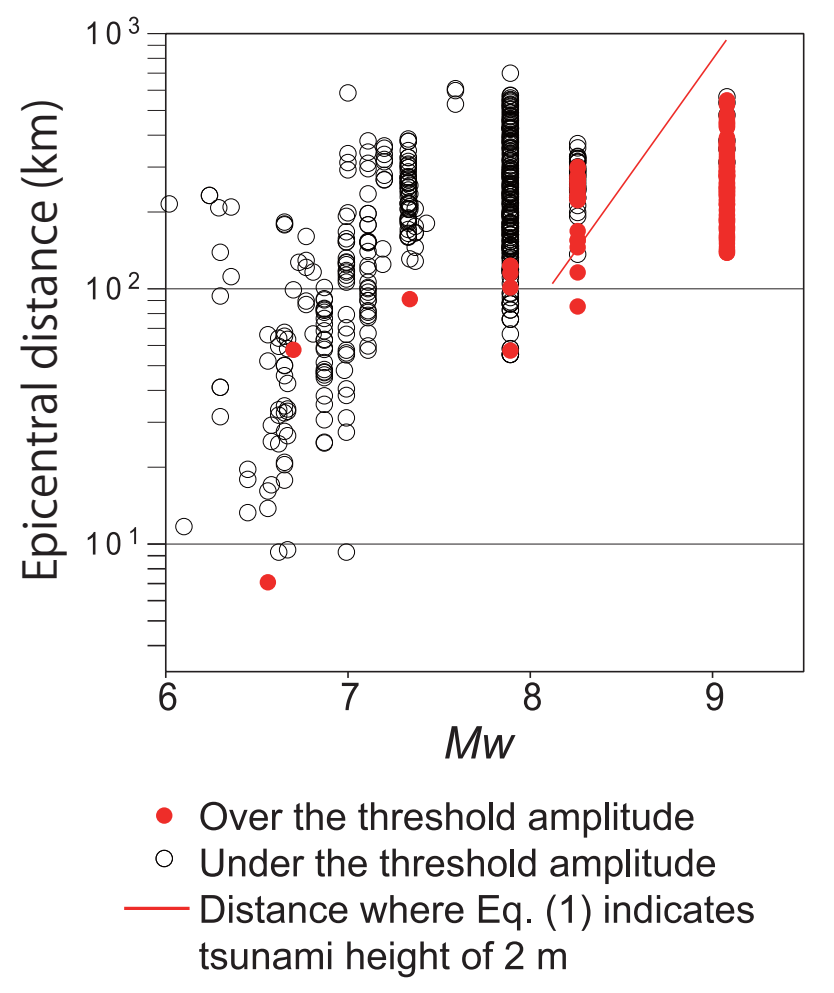

Figure 3. Data distribution of the maximum vertical displacement amplitude. Amplitude data which exceed the threshold value $(0.081 \mathrm{~m})$ are presented by red dots. The red line indicates the distance at which tsunami height is $2 \mathrm{~m}$ based on the Eq. (1) by Abe (1981).

and the black dot less than that. The red curve indicates the distance corresponding to $H=2 \mathrm{~m}$ based on Eq. (1). There are some data exceeding the threshold amplitude in small earthquakes. When the epicentral distance is short, amplitudes of a few data exceeded the threshold for some events even smaller than magnitude 7 . This situation corresponds to a false alarm.

Figure 4 presents the relationship between amplitude and epicentral distance for the 2003 Tokachi-oki earthquake $\left(M_{\mathrm{w}}\right.$ 8.3, thin circles) and the 2011 Great East Japan Earthquake ( $M_{\mathrm{w}}$ 9.1, thick circles). The dashed line indicates the threshold amplitude. For the 2003 Tokachi-oki earthquake, most of the data at stations up to about $200 \mathrm{~km}$ exceeded the threshold. At the same time, one datum at about $140 \mathrm{~km}$ from the epicenter did not exceed the threshold. For the 2011 Great East Japan Earthquake, most of the data exceeded the threshold up to about $400 \mathrm{~km}$. Source areas and observation points of these events are shown on maps in Sect. 3.2.

The false alarm due to large amplitude by a relatively small event is a problem in this method. Since the threshold of this study is a very rough estimation, false alarms are unavoidable. We tentatively checked other quantities such as peak ground velocity, duration of strong motion, and various com-

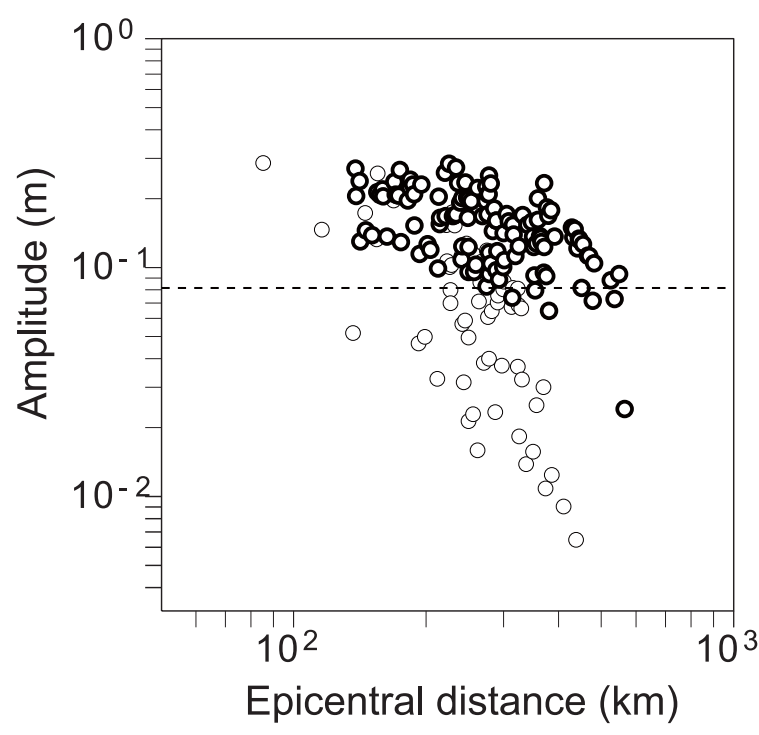

- The 2003 Tokachi-oki earthquake

- The 2011 Great East Japan Earthquake

Figure 4. Amplitude data distribution of the 2003 Tokachi-oki earthquake and the 2011 Great East Japan Earthquake. The dashed line indicates the threshold amplitude.

binations of these. No simple measure distinguished large earthquakes better than displacement amplitude.

\subsection{Application to recent major events}

The result is applied to several major earthquakes that occurred around Japan and Chile. The same data used in the previous section are referenced in the trials here for events around Japan. Data archived by the University of Chile (2015) are used for events around Chile. Figure 5 represents the results with the observed tsunami heights. These are almost all the events which occurred in the areas covered with strong motion networks and caused high tsunamis. The red dots denote stations located within $10 \mathrm{~km}$ of the shoreline with observational values above the threshold $(0.081 \mathrm{~m})$. The red open circle denotes a station that had an amplitude over the threshold but distant from the shoreline.

Regarding tsunami height, we referred to run-ups by Tanioka et al. (2004) for (a), Fritz et al. (2011) for (b), The 2011 Tohoku Earthquake Tsunami Joint Survey Group (2015) for (c), Catalán et al. (2015) for (d), and Aránguiz et al. (2015) for (e). The epicenters are denoted by blue dots, and the source areas are outlined by blue curves. Regarding source areas, we referred to Hatori (2004) for (a), Sladen (2015) for (b) (2.5 m slip contour), Yoshida et al. (2011) for (c) (5 m slip contour), Wei (2016) for (d) (1 m slip contour), and USGS (2016) for (e) (2.5 m slip contour). The open contours indicate large slips estimated at the edges of the assumed faults. 

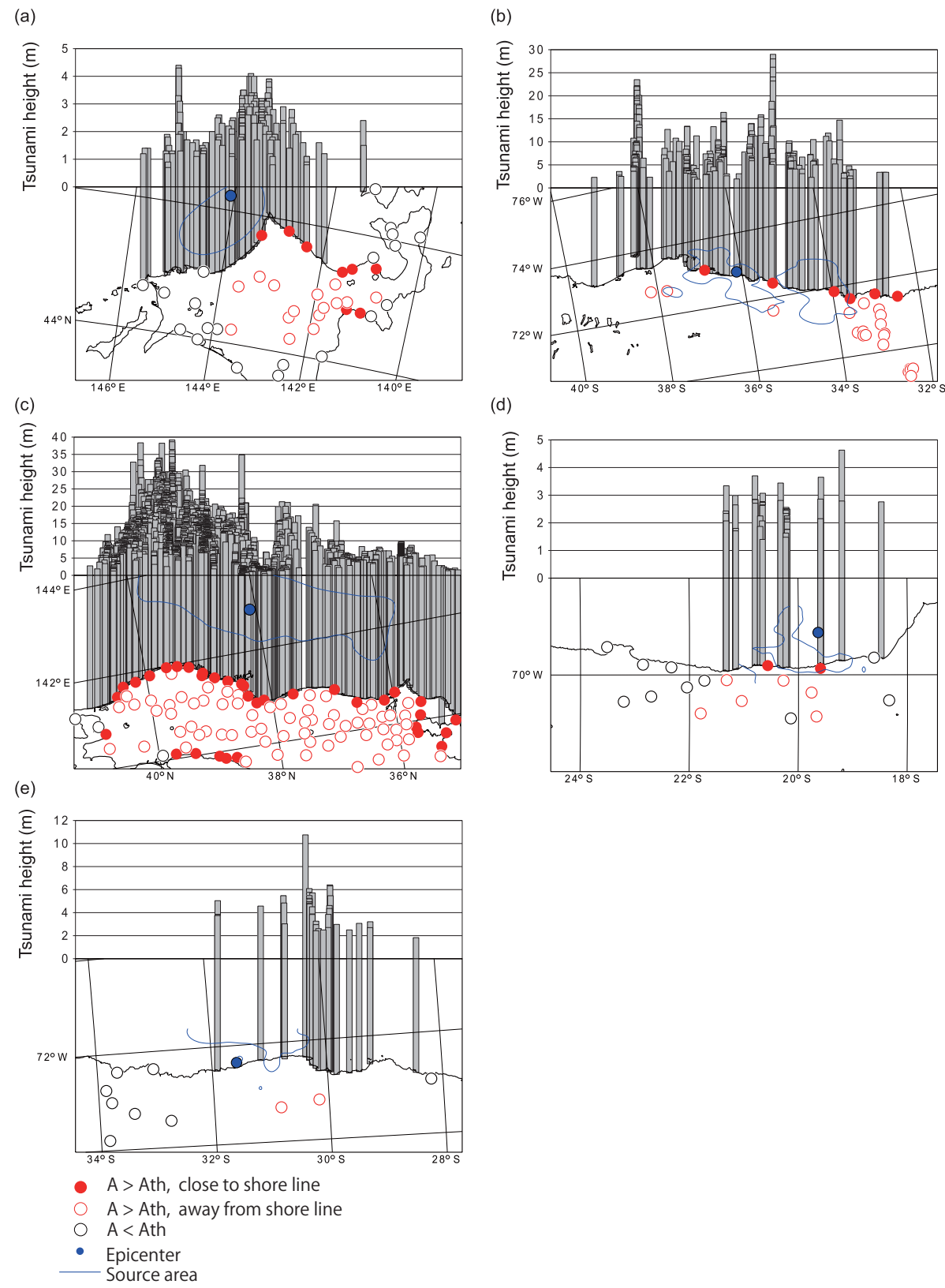

Figure 5. Map plot of the observational values for major earthquakes: (a) the 2003 Tokachi-oki earthquake $\left(M_{\mathrm{W}} 8.3\right)$, (b) the $2010 \mathrm{Maule}$ Earthquake $\left(M_{\mathrm{W}} 8.8\right)$, (c) the 2011 Great East Japan Earthquake $\left(M_{\mathrm{W}} 9.1\right)$, (d) the 2014 Iquique earthquake $\left(M_{\mathrm{W}} 8.1\right)$, and (e) the 2015 Illapel earthquake $\left(M_{\mathrm{W}} 8.3\right)$. Color is classified according to observed amplitude $(A)$ compared with threshold value $\left(A_{\text {th }}\right)$. The observed tsunami run-up heights are also indicated.

In Fig. 5, the observational values of many stations were generally above the threshold in areas of high tsunami. However, such stations did not cover all areas where high tsunamis were observed, and at some stations the observational values were less than the threshold but high tsunamis were observed. For the 2003 Tokachi-oki earthquake (Fig. 5a), the observational values were above the threshold in the areas of high-tsunami observation. However, there were some data lower than the threshold and close to which relatively high tsunamis were observed. For the 2010 Maule earthquake (Fig. 5b), the number of the stations was limited; however, the observational values were above the threshold in high-tsunami areas. For the 2011 Great East Japan Earthquake, the data were above the threshold in the areas of high-tsunami observation. However, the data above the threshold included those on the other side of the island. For the 2014 Iquique earthquake, the observational values exceeded the threshold in the area close to the event source. 

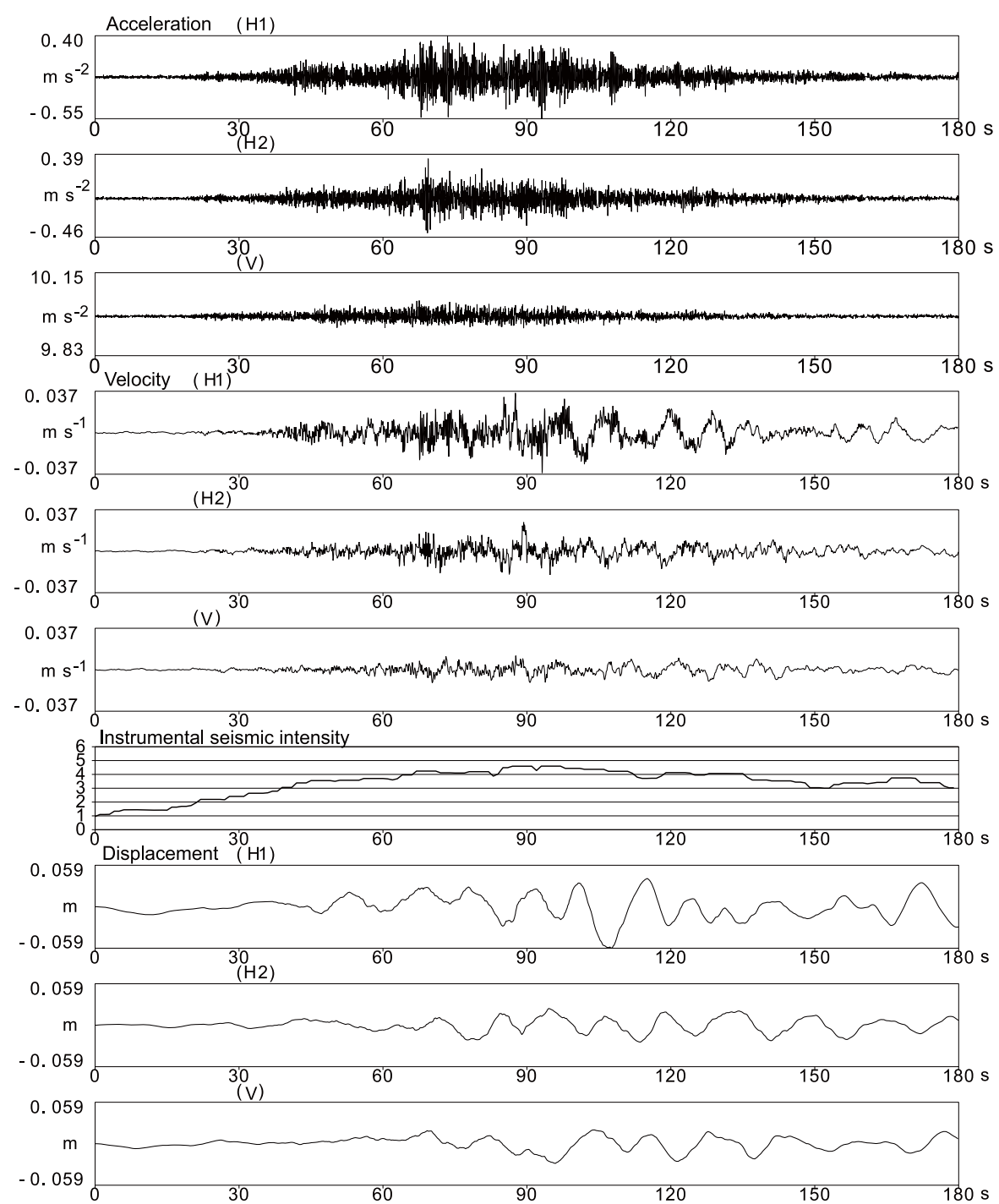

Figure 6. Seismic waves and instrumental seismic intensity obtained using prototype tsunami alarm equipment. Original acceleration records, velocity records for instrumental seismic intensity, instrumental seismic intensity, and displacement records are shown.

However, some data close to the source area were lower than the threshold. For the 2015 Illapel earthquake, the observational values were above the threshold in the area close to the highest tsunami.

These examples illustrate that the single-station method is effective in indicating a high-risk area of a large tsunami in many areas and that it cannot cover the whole area of high tsunami. Even though this method does not cover a possible disastrous area completely, an alert based on this method may induce caution regarding the possibility of a tsunami after a large earthquake. Moreover, although threshold values were estimated with data obtained in Japan, these examples indicate that this method is applicable to earthquakes around Chile, which is located in a similar tectonic setting as Japan.

We built prototype tsunami alarm equipment using an MEMS sensor and a small computer and tentatively observed ground motion with it. Records were obtained for the 2015 Illapel earthquake at the site of $33.03^{\circ} \mathrm{S}, 77.64^{\circ} \mathrm{W}$. Figure 6 indicates the observed acceleration, velocity for calculating instrumental seismic intensity, instrumental seismic intensity (Wald et al., 1999), and displacement. Since the observation point was far from the source area, the amplitude did not reach the threshold. Our equipment functioned also as a seismic intensity meter. ONEMI (2016) reported the modified Mercalli seismic intensity at this region (Valparaíso) as VI, which is close to the value obtained with the prototype equipment $(\mathrm{V})$. The result indicates that an MEMS sensor could properly detect the ground motion and could work for this purpose. 


\subsection{Slow events and limitation of the method}

A $20 \mathrm{~s}$ cutoff is considered to be enough for ordinary earthquakes of $M 8$. However, the spectrum level of the seismic wave of a $22 \mathrm{~s}$ period is lower for slow earthquakes than that of ordinary earthquakes (Polet and Kanamori, 2000). Twenty seconds would be too short for typical slow events. The 1896 Meiji-Sanriku earthquake is considered one such slow event (Kanamori, 1972). If a low-noise feedback-type accelerometer is used, longer periods such as 50 or $100 \mathrm{~s}$ can possibly be used. Usage of integrated displacement such as $M_{\mathrm{wp}}$ (Tsuboi et al., 1995) is an even better way. However, we leave these subjects out of this article because these are beyond the ability of a low-cost MEMS sensor.

False alarms and missed warnings are unavoidable with this method, as shown in Sects. 3.1 and 3.2. There is a tradeoff between the false alarms and missed warnings. If a message promoting confirmation of the official announcement is included in the alarm from the equipment, the problem of a false alert would be amended.

\section{Conclusions}

We proposed a method to differentiate earthquakes with disastrous tsunami potential from others using ground motion at a single site. With this method, displacement amplitude obtained with $20 \mathrm{~s}$ cutoff filter is used. It is possible to develop small equipment for this purpose using a low-cost MEMS sensor.

Application of this method to recent major earthquakes indicated that this method is partially effective in informing people of the possibility of a disastrous tsunami. Our sensors would not provide a perfect tsunami alarm system; instead, they would complement the official alarms. The priority should be placed on governmental information.

Data availability. The number of casualties of the 2011 Great East Japan Earthauke is available at https://www.npa.go.jp/archive/ keibi/biki/higaijokyo.pdf (National Police Agency, 2015). The data of hypocenters of the unified seismic catalog of Japan are available at http://www.data.jma.go.jp/svd/eqev/data/bulletin/hypo.html (Japan Meteorological Agency, 2015a). Acceleration records obtained by the seismic intensity meters of the Japan Meteorological Agency are available at http://www.data.jma.go.jp/ svd/eqev/data/kyoshin/jishin/index.html (Japan Meteorological Agency, 2015b). Acceleration records obtained by the University of Chile are available at http://evtdb.csn.uchile.cl (University of Chile, 2015). Slip distributions of the 2010 Maule Earthquake, the 2014 Iquique earthquake, and the 2015 Illapel earthquake are available at http://earthquake.usgs.gov/ (Sladen, 2015), http: //www.tectonics.caltech.edu/slip_history/2014_chile/index.html (Wei, 2016), and http://earthquake.usgs.gov/archive/product/ finitefault/us20003k7a/us/1442454346406/eb/20003k7a.fsp, respectively. Seismic intensity records in Chile are available at http://www.onemi.cl/informate/sismo-de-mayor-intensidad- en-las-regiones-de-metropolitana (ONEMI, 2016). Tsunami heights of the 2011 Great East Japan earthquake are available at http://www.coastal.jp/ttjt (The 2011 Tohoku Earthquake Tsunami Joint Survey Group, 2015).

Competing interests. The authors declare that they have no conflict of interest.

Acknowledgements. We are grateful to the two anonymous referees and the editor, B. D. Malamud, for their kind and thoughtful comments. This study used strong motion data obtained by the Japan Meteorological Agency and the University of Chile. We referred to hypocenter locations estimated using the seismic data of the National Research Institute for Earth Science and Disaster Prevention, Hokkaido University, Hirosaki University, Tohoku University, the University of Tokyo, Nagoya University, Kyoto University, Kochi University, Kyushu University, Kagoshima University, the National Institute of Advanced Industrial Science and Technology, the Tokyo metropolitan government, the Shizuoka prefectural government, the Kanagawa prefectural government, the city of Yokohama, Japan Agency for Marine-Earth Science and Technology, and the Japan Meteorological Agency. This study was partly supported by the SATREPS research project of "Enhancement of technology to develop tsunami-resilient community".

Edited by: B. D. Malamud

Reviewed by: two anonymous referees

\section{References}

Abe, K.: Physical size of tsunamigenic earthquakes of the northwestern Pacific, Phys. Earth Planet. In., 27, 194-205, doi:10.1016/0031-9201(81)90016-9, 1981.

Allen, R. M. and Kanamori, H.: The potential for earthquake early warning in southern California, Science, 300, 786-789, doi:10.1126/science.1080912, 2003.

Aránguiz, R., González, G., González, J., Catalán, P. A., Cienfuegos, R., Yagi, Y., Okuwaki, R., Urra, L., Contreras, K., Rio, I. D., and Rojas, C.: The 16 September 2015 Chile Tsunami from the post-tsunami survey and numerical modeling perspectives, Pure Appl. Geophys., 173, 333-348, doi:10.1007/s00024-015-12254, 2016

Catalán, P. A., Aránguiz, R., González, G., Tomita, T., Cienfuegos, R., González, J., Shrivastava, M. N., Kumagai, K., Mokrani, C., Cortés, P., and Gubler, A.: The 1 April 2014 Pisagua tsunami: Observations and modeling, Geophys. Res. Lett., 42, 2918-2925, doi:10.1002/2015GL063333, 2015.

Dobry, R., Idriss, I. M., and Ng, E.: Duration characteristics of horizontal components of strong-motion earthquake records, B. Seismol. Soc. Am., 68, 1487-1520, 1978.

Dziewonski, A. M., Chou T.-A., and Woodhouse, J. H.: Determination of earthquake source parameters from waveform data for studies of global and regional seismicity, J. Geophys. Res., 86, 2825-2852, doi:10.1029/JB086iB04p02825, 1981.

Ekström, G., Nettles, M., and Dziewonski, A. M.: The global CMT project 2004-2010: Centroid-moment tensors for 
13,017 earthquakes, Phys. Earth Planet. In., 200-201, 1-9, doi:10.1016/j.pepi.2012.04.002, 2012.

Fritz, H. M., Petroff, C. M., Catalán, P. A., Cienfuegos, R., Winckler, P., Kalligeris, N., Weiss, R., Barrientos, S. E., Meneses, G., Valderas-Bermejo, C., Ebeling, C., Papadopoulos, A., Contreras, M., Almar, R., Dominguez, J. C., and Synolakis, C. E.: Field survey of the 27 February 2010 Chile tsunami, Pure Appl. Geophys., 168, 1989-2010, doi:10.1007/s00024-011-0283-5, 2011.

Hara, T.: Magnitude determination using duration of high frequency energy radiation and displacement amplitude: application to tsunami earthquakes, Earth Planets Space, 59, 561-565, doi:10.1186/BF03352718, 2007.

Hatori, T.: Size and source area of 2003 Tokachi-oki earthquake, Research Reports of Tsunami Engineering, Disaster Control Research Center, Tohoku University, 21, 93-98, 2004 (in Japanese).

Izutani, Y. and Hirasawa, T.: Use of strong motion duration for rapid evaluation of fault parameters, J. Phys. Earth, 35, 171-190, doi:10.4294/jpe1952.35.171, 1987.

Japan Meteorological Agency: The unified seismic catalog of Japan, http://www.data.jma.go.jp/svd/eqev/data/bulletin/hypo.html, last access: 12 February 2015a.

Japan Meteorological Agency: Strong motion data, http://www. data.jma.go.jp/svd/eqev/data/kyoshin/jishin/index.html, last access: 12 February 2015 b.

Kanamori, H.: Mechanism of tsunami earthquakes, Phys. Earth Planet. In., 6, 346-359, doi:10.1016/0031-9201(72)90058-1, 1972.

Katsumata, A., Ueno, H., Aoki, S., Yoshida, Y., and Barrientos, S.: Rapid magnitude determination from peak amplitudes at local stations, Earth Planets Space, 65, 843-853, doi:10.5047/eps.2013.03.006, 2013.

Moroi, T. and Takemura, M.: Mortality estimation by causes of death due to the 1923 Kanto Earthquake, Journal of Japan Association for Earthquake Engineering, 4, 21-35, doi:10.5610/jaee.4.4_21, 2004. (in Japanese)

National Police Agency: Damages by the 2011 off the Pacific coast of Tohoku earthquake and measures implemented by the police, https://www.npa.go.jp/archive/keibi/biki/higaijokyo.pdf, last access: 17 September 2015.

Odaka, T., Ashiya, K., Tsukada, S., Sato, S., Ohtake, K., and Nozaka, D.: A new method of quickly estimating epicentral distance and magnitude from a single seismic record, B. Seismol. Soc. Am., 93, 526-532, doi:10.1785/0120020008, 2003.

ONEMI: Earthquake of greater intensity between the regions of Atacama and La Araucania, http://www.onemi.cl/informate/, last access: 30 March 2016.
Polet, J. and Kanamori, H.: Shallow subduction zone earthquakes and their tsunamigenic potential, Geophys. J. Int. 142, 684-702, doi:10.1046/j.1365-246x.2000.00205.x, 2000.

Sladen A.: Preliminary Result $02 / 27 / 2010\left(M_{\mathrm{W}} 8.8\right)$ Chile, Source Models of Large Earthquakes, http://www.tectonics.caltech.edu/ slip_history/2010_chile/index.html, last access: 9 December 2015.

Tanioka, Y., Nishimura, Y., Hirakawa, K., Imamura, F., Abe, I., Abe, Y., Shindou, K., Matsutomi, H., Takahashi, T., Imai, K., Harada, K., Namegawa, Y., Hasegawa, Y., Hayashi, Y., Nanayama, F., Kamataki, T., Kawata, Y., Fukasawa, Y., Koshimura, S., Hada, Y., Azumai, Y., Hirata, K., Kamikawa, A., Yoshikawa, A., Shiga, T., Kobayashi, M., and Masaka, S.: Tsunami run-up heights of the 2003 Tokachi-oki earthquake, Earth Planets Space, 56, 359-365, doi:10.1186/BF03353065, 2004.

The 2011 Tohoku Earthquake Tsunami Joint Survey Group: The 2011 off the Pacific coast of Tohoku earthquake tsunami information, http://www.coastal.jp/ttjt, last access: 6 December 2015.

Trifunac, M. D. and Brady, A. G.: A study on the duration of strong earthquake ground motion, B. Seismol. Soc. Am., 65, 581-626, 1975.

Tsuboi, S., Abe, K., Takano, K., and Yamanaka, Y.: Rapid determination of $M_{\mathrm{W}}$ from broadband $\mathrm{P}$ waveforms, B. Seismol. Soc. Am., 85, 606-613, 1995.

University of Chile: Registration of siginificant events, http://evtdb. csn.uchile.cl, last access: 17 October 2015.

Usami, T.: Materials for comprehensive list of destructive earthquakes in Japan [416]-2001 [Latest Edition], University of Tokyo Press, Tokyo, 605 pp., 2003 (in Japanese).

USGS: Preliminary finite fault results for the Sep 16, 2015 $M_{\mathrm{W}} 8.346 \mathrm{~km} \mathrm{~W}$ of Illapel, Chile Earthquake (Version 1), http://earthquake.usgs.gov/archive/product/finite-fault/ us20003k7a/us/1442454346406/web/20003k7a.fsp, last access: 15 February 2016.

Wald, D. J., Quitoriano, V., Heaton, T. H., and Kanamori, H.: Relationships between peak ground acceleration, peak ground velocity, and modified Mercalli intensity in California, Earthq. Spectra, 15, 557-564, doi:10.1193/1.1586058, 1999.

Wei, S.: Apr./01/2014 ( $M_{\mathrm{W}}$ 8.1), Iquique, Chile, Source Models of Large Earthquakes, http://www.tectonics.caltech.edu/slip_ history/2014_chile/index.html, last access: 15 February 2016.

Yoshida, Y., Ueno, H., Muto, D., and Aoki, S.: Source process of the 2011 off the Pacific coast of Tohoku Earthquake with the combination of teleseismic and strong motion data, Earth Planets Space, 63, 565-569, doi:10.5047/eps.2011.05.011, 2011. 